\title{
Highly selective two-step laser ionization schemes for the analysis of actinide mixtures
}

\author{
Nina Kneip ${ }^{1,2}$. Christoph E. Düllmann 2,3,4 Vadim Gadelshin $^{1,5} \cdot$ Reinhard Heinke $^{1,6}$. \\ Christoph Mokry ${ }^{2,3}$. Sebastian Raeder ${ }^{3,4}$. Jörg Runke ${ }^{2,4}$. Dominik Studer ${ }^{1}$. \\ Norbert Trautmann ${ }^{2} \cdot$ Felix Weber $^{1} \cdot$ Klaus Wendt $^{1}$
}

Published online: 16 March 2020

(C) The Author(s) 2020

\begin{abstract}
Resonance ionization mass spectroscopy has proven to be a very efficient and selective method for the spatially resolved ultratrace determination of actinide contaminations, and the analysis of specific element and isotopic distributions on surfaces and environment particles. We report on the identification of highly element-selective optical excitation schemes identified for this purpose, with a particular focus on the precise determination of the isobaric ratios of ${ }^{235} \mathrm{U}$ to ${ }^{239} \mathrm{Pu}$ as well as ${ }^{243} \mathrm{Am}$ to ${ }^{241} \mathrm{Pu}$. The chosen two-step ionization schemes were characterized with respect to their element selectivity on synthetic multielement actinide mixtures, with an element ratio $\mathrm{Pu}: \mathrm{Am}: \mathrm{U}$ of $1: 10: 10^{4}$, a composition which is typical, e.g., for spent nuclear reactor fuels.
\end{abstract}

Keywords Laser spectroscopy · Mass spectrometry · Actinides · Isotope ratio · Multi-element mixture

\section{Introduction}

The determination of ultra-trace amounts of actinide elements in environmental samples is of major relevance for the investigation of the chemical and migratory behaviour of actinides

This article is part of the Topical Collection on Proceedings of PLATAN 2019, 1st International Conference, Merger of the Poznan Meeting on Lasers and Trapping Devices in Atomic Nuclei Research and the International Conference on Laser Probing, Mainz, Germany 19-24 May 2019

Edited by Krassimira Marinova, Michael Block, Klaus D.A. Wendt and Magdalena Kowalska

\section{Nina Kneip}

nina.kneip@uni-mainz.de

1 Institute of Physics, Johannes Gutenberg University, Mainz, 55099, Germany

2 Department of Chemistry - TRIGA Site, Johannes Gutenberg University, Mainz, 55099, Germany

3 Helmholtz-Institut, Mainz, 55099, Germany

4 GSI Helmholtzzentrum für Schwerionenforschung GmbH, Darmstadt, 64291, Germany

5 Institute of Physics and Technology, Ural Federal University, Yekaterinburg, 620002, Russia

6 Institute for Nuclear and Radiation Physics, KU Leuven, Heverlee, 3001, Belgium 
in the context of the assessment of a suitable long-term repository for radioactive waste. The experimental approach is based on resonant laser ionization in combination with mass spectrometry [1]. For this technique, an efficient and specifically element-selective laser ionization step is required for each investigated chemical element. By the use of a fullyautomated tuning unit within a grating-based Ti:sapphire laser with intra-cavity frequency doubling, individual ionization schemes of different elements can be addressed one after the other. New ionization schemes have been tested with synthetic actinide mixtures, and their overall detection efficiency and elemental selectivity has been characterized. The samples were composed of $10^{16}$ atoms of uranium with a $1: 1$ ratio of ${ }^{235} \mathrm{U}:{ }^{238} \mathrm{U}, 10^{13}$ atoms of americium with a $1: 1$ ratio of ${ }^{241} \mathrm{Am}:{ }^{243} \mathrm{Am}$ and $10^{12}$ atoms of plutonium in total with a ratio of $1: 0.13: 0.56: 0.15$ for ${ }^{239} \mathrm{Pu}:{ }^{240} \mathrm{Pu}:{ }^{241} \mathrm{Pu}:{ }^{242} \mathrm{Pu}$, which resembles a realistic composition of spent nuclear fuel in the ratio of elements [2]. The specific goal of this study was the demonstration of resolving the different isobaric interferences on the masses 238 and 241, which hamper the application of the majority of competing analytical techniques.

\section{Experimental setup}

The development of the ionization schemes of uranium, plutonium, and americium and their characterization in a multi-element mixture were performed at the Mainz atomic beam unit (MABU), applying a quadrupole mass spectrometer in combination with a pulsed Ti:sapphire laser system [3]. The sample solution of typically $3 \mu \mathrm{L}$ is pipetted onto a $5 \times 5 \mathrm{~mm}^{2}$ zirconium foil with $0.025 \mathrm{~mm}$ foil thickness and then placed inside a tantalum tube furnace of $30 \mathrm{~mm}$ length and $3 \mathrm{~mm}$ diameter, which is heated resistively to the optimum evaporation temperatures of the actinides under study which all amount to about $2000 \mathrm{~K}$. At sufficiently high temperatures, the sample atoms are evaporized and subsequently resonantly ionized by the incident laser beams. The ions are extracted by a $150 \mathrm{~V}$ extraction potential, undergo ion beam formation, are separated in a quadrupole mass spectrometer, and are finally detected by a channel electron multiplier. The suppression factor for neighbouring isotopes is about $10^{3}$. The experimental setup as shown in Fig. 1 is identical to the one previously used for the development of three-step ionization schemes and for ultra-trace analysis of actinides [3]. Two-step ionization schemes with high efficiency and reasonable element selectivity were identified, simplifying the experimental expenditure and enhancing long term reliability significantly. In contrast to formerly favored three-step ionization schemes, the application of such two-step ionization schemes using the new fully automated grating-tuned Ti:sapphire lasers featuring intra-cavity second harmonic generation (IC-SHG) [4] enable a quick and easy tuning of the ionization schemes. The lasers are pumped by the second harmonic of a Nd:YAG laser ${ }^{1}$ at $532 \mathrm{~nm}$ at a pulse repetition rate of $10 \mathrm{kHz}$. The basic resonator design, excluding the intra-cavity SHG, is decribed in [5]. The spectral with of each laser amounts to up to $7 \mathrm{GHz}$ reducing disturbing influences of the isotope shift on the respective ionization rate. The laser settings for a specific element can be set up within 1 to 2 min by closed-loop feedback stabilization techniques of both the laser frequency and IC-SHG phase matching. The fundamental frequency of each laser was measured with a wavelength meter. ${ }^{2}$

\footnotetext{
${ }^{1}$ Photonics Industries DM100-532.

${ }^{2}$ High Finesse WS6-600
} 


\section{Spectroscopy and ionization scheme development}

As the actinides have a very high spectral line density, there is a variety of possible excitation schemes for the individual element. A specific challenge is the identification of resonances which circumvent any interferences with lines of other actinides. This is particulary important for the measurement of accurate isotope ratios and for avoiding isobaric contaminations, specifically, e.g., in the case of the neighbouring isotopes ${ }^{239} \mathrm{Pu}$ and ${ }^{238} \mathrm{U}$ or the isobars ${ }^{241} \mathrm{Pu}$ and ${ }^{241} \mathrm{Am}$. Initially, ionization schemes were developed with isotopically pure ${ }^{238} \mathrm{U}$, ${ }^{244} \mathrm{Pu}$, and ${ }^{241} \mathrm{Am}$ samples. For the scheme development of uranium and americium, known first steps from literature were used and afterwards auto-ionizing steps were searched by systematic wide-range scanning of the second laser. The resonances yielding the highest ionization rate were employed as final steps for the respective schemes.

For the ionization of plutonium, the challenge was to identify resonances for the first and second excitation steps in spectral regions with no uranium resonances. In total, the energy range of $23600-25200 \mathrm{~cm}^{-1}$ was scanned on a pure plutonium sample by detuning the first step excitation laser, with a setting of the second laser for providing sufficient photon energy for non-resonant ionization into the continuum. The same spectral range was also investigated on a pure uranium sample. The measured resonances in plutonium and uranium were compared and the three ground state resonances at $23037 \mathrm{~cm}^{-1}$ into $5 f^{5} 6 d 7 s^{2}(J=1)^{o}$, at $23766 \mathrm{~cm}^{-1}$ into $5 f^{6} 7 d 7 p^{7} D_{1}^{o}$, and at $24188 \mathrm{~cm}^{-1}$ into $5 f^{5} 6 d^{2} 7 s$ $(J=1)^{o}[7]$ were selected as possible first plutonium excitation steps preventing direct uranium interferences. For these three first steps, the range from well below up to about $500 \mathrm{~cm}^{-1}$ above the ionization potential of plutonium was spectroscopically investigated by scanning using the second laser. In this range, no significant background from uranium was expected due to the fact that its ionization potential is higher by about $1600 \mathrm{~cm}^{-1}$. In order to identify and afterwards exclude interfering uranium resonances, this spectral range was also investigated for the pure uranium. As an example, the second plutonium step scan starting from the $23037 \mathrm{~cm}^{-1}$ level is shown in Fig. 2. Here, the spectral range of 24500 $-25000 \mathrm{~cm}^{-1}$ was measured once in a pure uranium sample (red spectrum) and once in a pure plutonium sample (blue spectrum) with significantly less well-resolved resonances starting from the $23037 \mathrm{~cm}^{-1}$.

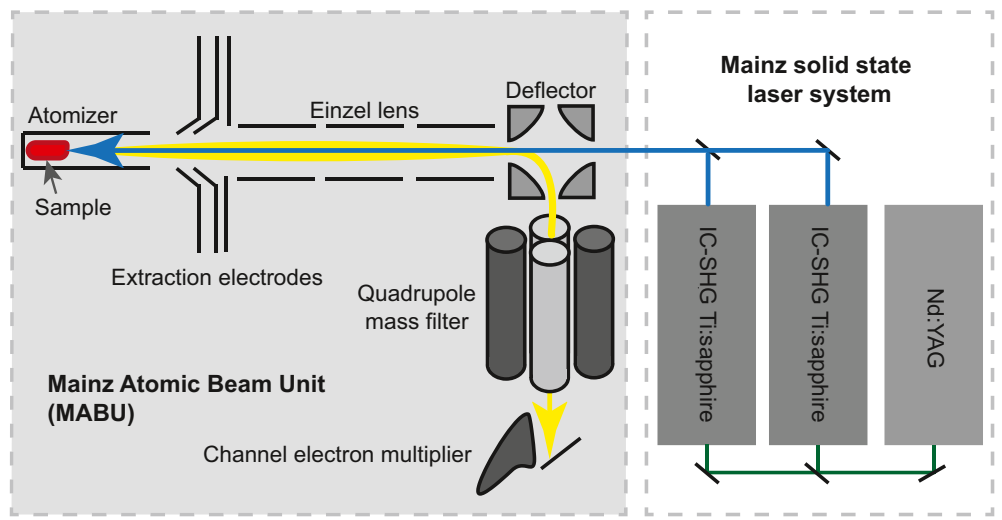

Fig. 1 Experimental setup of the MABU, used for in-source spectroscopy of uranium, plutonium, and americium. The apparatus is coupled to an IC-SHG (intra-cavity second harmonic generation) Ti:sapphire laser system. The laser beams are shown in blue and the ion beam in yellow 


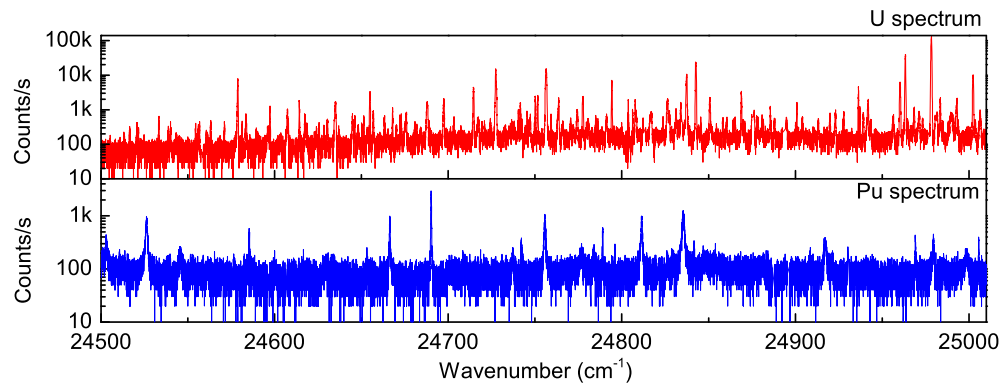

Fig. 2 Scan of the first excited step of uranium and the second exitation step of plutonium in the spectral range from $24500 \mathrm{~cm}^{-1}$ to $25000 \mathrm{~cm}^{-1}$

Furthermore, the three different ionization schemes identified for plutonium were individually characterized with respect to selectivity and efficiency in measurements on the uranium/plutonium/americium actinide mixtures. The final two-step ionization schemes of optimum performance, as selected for uranium, plutonium, and americium, are given in Table 1. To determine the saturation power of each step, the ion signal $I$ was measured as function of laser power $P$ and the resulting dependence was fitted using a conventional saturation curve according to

$$
I(P)=C_{0}+C_{1} \cdot \frac{1}{1+P_{\text {sat }} / P}+C_{2} \cdot P
$$

as introduced, e.g., in [9]. $C_{0}$ describes the background, $C_{2}$ the slope of a property linear to the laser power $P$. The saturation power $P_{\text {sat }}$ describes the laser power needed to reach half the ionization rate of the convergence amplitude $C_{1}$.

The saturation power was measured with full illumination of the atomizer orifice of $3 \mathrm{~mm}$ diameter and a laser pulse length of 30-50 ns.

\section{Selective characterization of ionization schemes in an actinide mixture}

The element selectivity of the newly identified two-step ionization schemes was studied using the mixture of actinides described above, with an element composition which is representing spent nuclear fuel [2]. Table 2 gives the detailed composition of the sample, which was prepared at the Institute of Nuclear Chemistry at Johannes Gutenberg University Mainz. Figure 3 shows the measured mass spectra of the sample.

Since the actinides have different evaporation curves and vapor pressures at a given temperature, the mass spectra were measured at different heating temperatures, corresponding

Table 1 First-exitation-steps (FES) and second-exitation-steps (SES) for the newly identified two-step ionization schemes for uranium, plutonium, and americium, as well as the individual saturation powers $P_{\text {sat }}$

\begin{tabular}{llllll}
\hline Element & FES $\left[\mathrm{cm}^{-1}\right]$ & $\mathrm{P}_{\text {sat }}[\mathrm{mW}]$ & Lit & SES $\left[\mathrm{cm}^{-1}\right]$ & $\mathrm{P}_{\text {sat }}[\mathrm{mW}]$ \\
\hline $\mathrm{U}$ & $25235.62(4)$ & $4.1(8)$ & {$[6]$} & $24754.10(5)$ & - \\
$\mathrm{Pu}$ & $24188.45(4)$ & $6.6(4)$ & {$[7]$} & $24690.34(5)$ & $74(17)$ \\
$\mathrm{Am}$ & $23436.98(4)$ & $2.0(1)$ & {$[8]$} & $25033.38(7)$ & $62(2)$ \\
\hline
\end{tabular}


Table 2 Actinide mixture composition, as determined with $\alpha$-spectroscopy

\begin{tabular}{ll}
\hline Nuclide & Atom number \\
\hline${ }^{235} \mathrm{U}$ & $3.0 \cdot 10^{16}$ \\
${ }^{238} \mathrm{U}$ & $3.0 \cdot 10^{16}$ \\
${ }^{239} \mathrm{Pu}$ & $5.4 \cdot 10^{12}$ \\
${ }^{240} \mathrm{Pu}$ & $7.4 \cdot 10^{11}$ \\
${ }^{241} \mathrm{Pu}$ & $3.0 \cdot 10^{12}$ \\
${ }^{242} \mathrm{Pu}$ & $8.1 \cdot 10^{11}$ \\
${ }^{241} \mathrm{Am}$ & $1.0 \cdot 10^{13}$ \\
${ }^{243} \mathrm{Am}$ & $1.0 \cdot 10^{13}$ \\
\hline
\end{tabular}

The uncertainty of the atom numbers is $\leq 10 \%$. This element composition is close to that determined in spent fuel rods of WWER-440, WWER-1000 and RBMK-1000 reactors [3]

to optimum release of an element into an atomic gas (A, $\mathbf{C}$ measured at $1210(5){ }^{\circ} \mathrm{C}$ and B, D measured at $\left.1490(5){ }^{\circ} \mathrm{C}\right)$. The temperature of the atomizer was measured through a window of the vacuum chamber with a two colour pyro meter. ${ }^{3}$ The spectra $\mathbf{A}$ and $\mathbf{B}$ were measured using the laser scheme for resonant ionization of plutonium, with specific tuning for the isotope ${ }^{241} \mathrm{Pu}$. The mass spectra show the expected signal ratios for all plutonium isotopes ${ }^{239,240,241,242} \mathrm{Pu}$. With higher overall count rate, spectrum $\mathbf{B}$ also shows a minor contamination of ${ }^{243} \mathrm{Am}$ and ${ }^{244} \mathrm{Pu}$. This indication of ${ }^{243} \mathrm{Am}$ is a result of beginning surface ionization due to the high temperature of the atomizer. The ${ }^{244} \mathrm{Pu}$-contamination is a result of a memory effect in the atomizer of previous spectroscopic investigations on this isotope. Spectrum $\mathbf{C}$ with lasers tuned to americium shows the expected americium isotopes at masses 241 and 243 without any contamination by other elements. The spectrum $\mathbf{D}$ with lasers on resonance for uranium exhibits mass peaks of the resonantly-ionized uranium isotopes ${ }^{235} U$ and ${ }^{238} U$ and shows americium contaminations at masses 241 and 243 which once again stem from beginning surface ionization.

A suppressing factor $S$, computed as signal versus the contamination $N_{\text {contamination, }}$ is given by

$$
S=\frac{N_{\text {resonantly-ionized }}}{N_{\text {contamination }}} \cdot X_{\text {sample composition }}
$$

for plutonium against uranium or for plutonium against americium. $N_{\text {contamination }}$ and $N_{\text {resonantly-ionized }}$ correspond to the respective count rates per second for signal and selected interference and $X_{\text {sample composition }}$ to the ratio of the number of atoms of these isotopes within the initial sample. Figure 4 visualizes the results of the measurements. The suppression factor characterizes the selectivity of the ionization scheme, which is of specific importance for the correct determination of the isotopic ratios, specifically of relevance here in the case of plutonium. The evolution of the count rate of the isotopes ${ }^{235} \mathrm{U},{ }^{239} \mathrm{Pu}$, and ${ }^{243} \mathrm{Am}$ at different atomizer temperatures is plotted in the lower graph, while the upper graph shows the corresponding suppression factors $S_{\mathrm{Pu}-239 / \mathrm{U}-235}$ and $S_{\mathrm{Pu}-239 / \mathrm{Am}-243}$ as function of the temperature. A suppression ratio $S_{\mathrm{Pu}-239 / \mathrm{Am}-243}$ of 3 orders of magnitude was demonstrated. It is widely constant in the temperature range from $1600{ }^{\circ} \mathrm{C}$ to $1800{ }^{\circ} \mathrm{C}$. A suppression factor of $S_{\mathrm{Pu}-239 / \mathrm{U}-235} \geq 10^{8}$ was reached in the lower temperature range from

\footnotetext{
${ }^{3}$ Heimann KT-81R.
} 

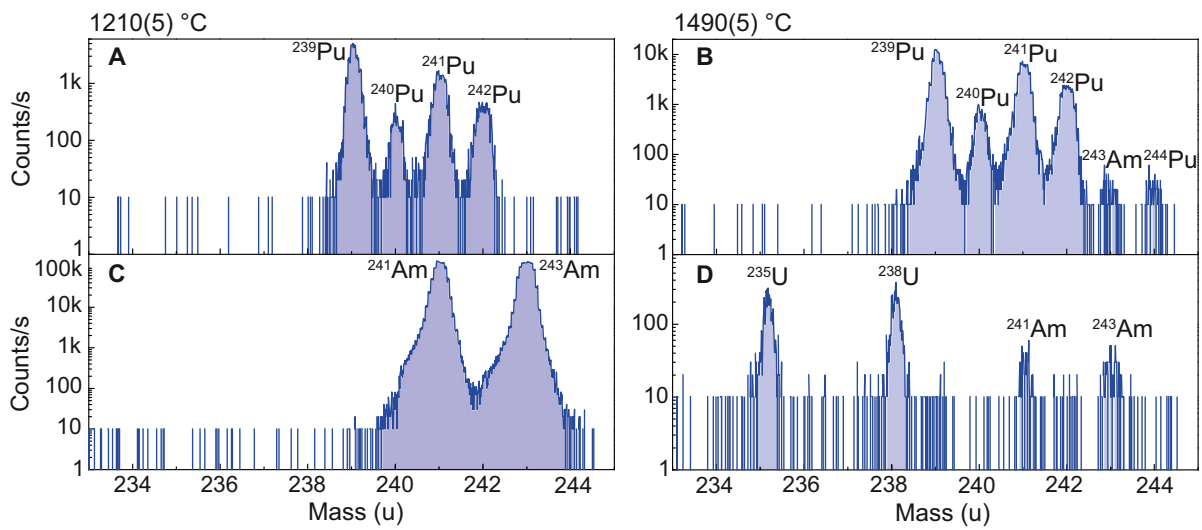

Fig. 3 Measured mass spectra for the actinide mixture given in Table 2. The lasers were optimized for the resonances of the isotopes ${ }^{241} \mathrm{Pu}$ in plots $\mathbf{A}$ and $\mathbf{B},{ }^{241} \mathrm{Am}$ in plot $\mathbf{C}$, and ${ }^{238} \mathrm{U}$ in plot $\mathbf{D}$

$1600{ }^{\circ} \mathrm{C}$ to $1680{ }^{\circ} \mathrm{C}$. With increasing temperature above $1700{ }^{\circ} \mathrm{C}$, a slightly increasing uranium contamination from unspecific ionization processes was observed, influencing and steadily reducing this suppression factor. This is caused by the steadily increasing evaporation and atomization of uranium in this temperature range [10]. Nevertheless, even for maximum oven temperature of $1800^{\circ} \mathrm{C}$, still a value of $S_{\mathrm{Pu}-239 / \mathrm{U}-235}$ well above $10^{5}$ was maintained.

\section{Summary and outlook}

New efficient two-step ionization schemes for uranium, plutonium, and americium using intra-cavity frequency-doubled Ti:sapphire lasers were identified and characterized in measurements on synthetic actinide mixtures. In order to verify the element selectivity of the ionization schemes, the suppression factors $S_{\mathrm{Pu}-239 / \mathrm{U}-235}$ and $S_{\mathrm{Pu}-239 / \mathrm{Am}-243}$ were determined. Suppression of uranium by up to eight orders of magnitude and of americium by three orders of magnitude, both with respect to plutonium, could be demonstrated. These

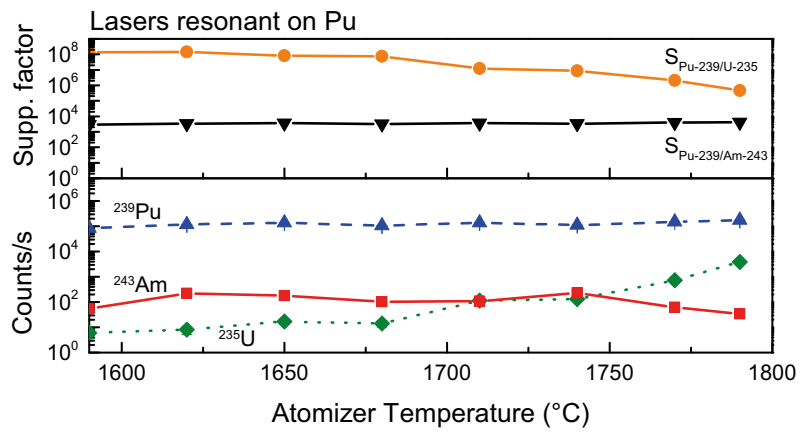

Fig. 4 Lower graph: Progress of the count rate of resonantly ionized ${ }^{239} \mathrm{Pu}$, as well as the ${ }^{235} \mathrm{U}$ and ${ }^{243} \mathrm{Am}$ signals caused by near-resonant ionization. Upper graph: Suppression factors $S_{\mathrm{Pu}-239 / \mathrm{U}-235}$ and $S_{\mathrm{Pu}-239 / \mathrm{Am}-243}$ as function of temperature 
high values are the basis for the correct determination of isotopic ratios as valuable quantity, e.g., for sample origin determination. Despite of the generally high spectral line density in the actinides, a high element selectivity could thus be demonstrated with the newly-chosen two step ionization schemes, rendering them directly applicable for sensitive analytical measurements.

Acknowledgements Open Access funding provided by Projekt DEAL. Support by the Bundesministerium für Bildung und Forschung (BMBF, Germany) under project number 05P15UMCIA is acknowledged.

Open Access This article is licensed under a Creative Commons Attribution 4.0 International License, which permits use, sharing, adaptation, distribution and reproduction in any medium or format, as long as you give appropriate credit to the original author(s) and the source, provide a link to the Creative Commons licence, and indicate if changes were made. The images or other third party material in this article are included in the article's Creative Commons licence, unless indicated otherwise in a credit line to the material. If material is not included in the article's Creative Commons licence and your intended use is not permitted by statutory regulation or exceeds the permitted use, you will need to obtain permission directly from the copyright holder. To view a copy of this licence, visit http://creativecommonshorg/licenses/by/4.0/.

\section{References}

1. Franzmann, M., Bosco, H., Hamann, L., Walther, C., Wendt, K.: Resonant laser-SNMS for spatially resolved and element selective ultra-trace analysis of radionuclides. J. Anal. At. Spectrom. 33(5), 730737 (2018). https://doi.org/10.1039/C7JA00423K

2. Makarova, T.P., Bibichev, B.A., Domkin, V.D.: Destructive analysis of the nuclide composition of spent fuel of WWER-440 WWER-1000, and RBMK-1000 reactors. Radiochemistry 50(4), 414-426 (2008). https://doi.org/10.1134/S1066362208040152

3. Raeder, S., Kneip, N., Reich, T., Studer, D., Trautmann, N., Wendt, K.: Recent developments in resonance ionization mass spectrometry for ultra-trace analysis of actinide elements. Radiochim. Acta 107(7), 645-652 (2019). https://doi.org/10.1515/ract-2019-0001

4. Sonnenschein, V., Moore, I.D., Pohjalainen, I., Reponen, M., Rothe, S., Wendt, K.: Intracavity frequency doubling and difference frequency mixing for pulsed ns Ti: sapphire laser systems at on-line radioactive ion beam facilities. Journal of the Physical Society of Japan. https://doi.org/10.7566/JPSCP.6.030126 (2015)

5. Teigelhöfer, A., Bricault, P., Chachkova, O., Gillner, M., Lassen, J., Lavoie, J.P., Li, R., Meißner, J., Neu, W., Wendt, K.D.A.: Grating tuned Ti:Sa laser for in-source spectroscopy of Rydberg and autoionizing states. Hyperfine Interactions 196(1-3), 161-168 (2010). https://doi.org/10.1007/s10751-010-0171-X

6. Kies, C.C.: Preliminary description and analysis of the first spectrum of uranium. Part of Journal of Research of the National Bureau of Standards (37), 57-72 (1946)

7. Blaise, J., Fred, M., Gutmacher, R.G.: Recent developments in resonance ionization mass spectrometry for ultra-trace analysis of actinide elements. Journal of the Optical Society of America B 3(3), 403 (1986). https://doi.org/10.1364/JOSAB.3.000403

8. Fred, M., Tomkins, F.S.: Preliminary term analysis of Am i and Am ii spectra. J. Opt. Soc. Am. 47(12), 1076 (1957). https://doi.org/10.1364/JOSA.47.001076

9. Schneider, F., Chrysalidis, K., Dorrer, H., Düllmann, C.H.E., Eberhardt, K., Haas, R., Kieck, T., Mokry, C., Naubereit, P., Schmidt, S., Wendt, K.: Resonance ionization of holmium for ion implantation in microcalorimeters. Nucl. Instrum. Methods Phys. Res. Sect. B 376, 388-392 (2016). https://doi.org/10.1016/j.nimb.2015.12.012

10. Honig, R.: Vapor pressure data for solid and liquid elements. Radiochimica Acta 30(2), 285-305 (1969)

Publisher's note Springer Nature remains neutral with regard to jurisdictional claims in published maps and institutional affiliations. 